\title{
Fatal accident involving a welder employed by a shipping container company, associated with the use of tramadol and antidepressant agents
}

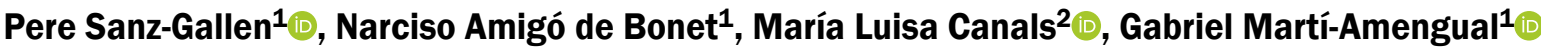

${ }^{1}$ Unit of Occupational Medicine and Toxicology, School of Medicine and Health Sciences of Barcelona, University of Barcelona, Spain ${ }^{2}$ Maritime Health Unit, ISM Tarragona, Spain

\begin{abstract}
The widespread use of opioids for the treatment of moderate or severe acute and chronic pain has become a public health problem due to the physical and psychological dependence and tolerance they produce. The increasingly higher doses that patients require may reach toxic levels or lead to accidents, including fatalities.

We present the case of a welder who, while working for a shipping container company, fell from height without a safety harness and subsequently died as a result of a traumatic brain injury. Post-mortem examination revealed a cardiac blood tramadol concentration of $2.83 \mathrm{mg} / \mathrm{L}$, which is 3-4 times higher than the maximum therapeutic dose. The combined use of synthetic opioids and antidepressants may heighten the adverse neurological and psychiatric effects.

A review of the literature, identified studies, including previous reports of fatalities, supported our causal hypothesis of a serotonin syndrome. This syndrome can lead to a loss of cognitive and sensory capacity, interfere with decision-making ability, and produce mental confusion and dizziness, among other symptoms. In order to prevent harm to themselves and others, all persons who are currently taking these kinds of drugs should avoid dangerous tasks at work and must be advised by a physician regarding the type of activities that are safe for them to perform.
\end{abstract}

(Int Marit Health 2020; 71, 2: 109-113)

Key words: fatal outcomes, occupational accidents, poisoning, opioid abuse, antidepressant agents, drug-related side effects, adverse reactions

\section{INTRODUCTION}

The widespread use of opioids, especially for the treatment of moderate or severe acute and chronic pain, has become a public health problem in many countries. Notably, in the United States, there are increasing reports of fatalities among people prescribed these drugs, which produce both physical and psychological dependence [1]. In February 2017, the Spanish Medicines Agency AEMPS published a report on opioid use in our country during the period 2008-2015 [2], and data for 2010-2018 [3] are available on the Agency's website. The most widely used active substance in this class is tramadol (either alone or in combination with analgesics and anti-inflammatory drugs), accounting for $63.2 \%$ of prescribed analgesic opioids in 2018 [3].

A report published in January 2015 [4] by the Spanish Medicines Agency documented a 200\% increase in the use of antidepressants in Spain during the period 2000-2013. The data showed that the most widely used drugs of this class were selective serotonin reuptake inhibitors (SSRIs), followed by those classified as "other antidepressants", which accounted, respectively, for $70.4 \%$ and $29.7 \%$ of total antidepressant use in 2013 . Although only certain antidepressants may interfere with a person's ability to drive and/or carry out potentially dangerous tasks at work, many 
Table 1. Results for the main active substances found in blood samples from the deceased*

\begin{tabular}{lll}
\hline Active substance & Concentration in blood [mg/L] & Therapeutic concentration [mg/L] \\
\hline Tramadol & 2.83 & $0.1-0.8$ \\
Venlafaxine & 0.05 & $0.01-0.2$ \\
Midazolam** & 0.14 & $0.08-0.25$ \\
*A very low blood concentration of diazepam was also detected, $0.01 \mathrm{mg} / \mathrm{L}$ (therapeutic value is $0.02-4 \mathrm{mg} / \mathrm{L}$ ) & \\
**It was subsequently clarified that the paramedics had administered midazolam &
\end{tabular}

patients have prescribed them in combination with other psychotropic drugs, which increases the associated hazards.

There are only some recommendations by the "Driving Under the Influence of Drugs, Alcohol and Medicines" project (DRUID) in 2011 [5], on the effects of some medicines and driving. That is why, we have produced a guide that includes, in addition to driving, the main dangerous work activities for the worker himself and for other people [1]. In this case report we want to highlight the danger of tramadol.

Just to summarise this case report article. We describe the case of a fatal accident involving an employee of a shipping container company in the Port of Barcelona, in which the post-mortem examination showed a high blood concentration of tramadol and a concentration within the therapeutic range of venlafaxine.

\section{CASE REPORT}

\section{DESCRIPTION OF THE OCCUPATIONAL ACCIDENT}

The 41-year-old man had been working for the past 11 years for a shipping container company in the Port of Barcelona. At the time of the occupational accident (8 a.m.) he was working in the maintenance terminal of a freight shipping company, where his task was to raise the height of the upper gangway allowing access to the straddle carriers. The accident occurred while he was preparing the necessary material waiting for his work colleague arrival to start the task. The steel walkway unexpectedly gave way and, as he had not attached a safety harness, he fell from a height of $12.20 \mathrm{~m}$ to the floor of the maintenance terminal.

The emergency paramedics arrived 12 minutes after the accident and observed an open fracture of the left forearm, left otorrhagia and a traumatic brain injury. Standard resuscitation and treatment procedures were performed in situ to stabilise the patient's vital signs (cervical collar, cardio-pulmonary resuscitation manoeuvres and administration of $15 \mathrm{mg}$ of Midazolam). Later he was transferred by ambulance to the emergency department of a hospital in Barcelona (admitted at 9:40 a.m.).

The patient arrives at the Hospital in Coma (grade 3 of the Glasgow Coma Scale), hypotension, bradycardia, bilateral mydriasis, non-palpable pulses, intraoral blood, bilateral otorrhagia. Three litres of Ringer's serum and 4 vials of
Beriplex (combination of type II, VII, IX, XI coagulation factors) are administered. In a period of 40 minutes, the patient progresses to severe bradycardia and asystole, which is attempted to be reversed with a defibrillator, but it is not successful and the patient dies.

The main autopsy findings are a fracture of the skull base, a bilateral pulmonary contusion, and an open fracture of the left elbow.

Adams and Hirsch in 1993 published the 5 degrees of certainty according to the autopsy findings. Group 1 being the most certain and group 5 the least. This case is classified in group 1 (the cause of death is identified with the autopsy findings with absolute certainty and the mechanism of death is structurally demonstrable), these Adams and Hirsch grades are well commented by Teijeira et al., 2006 [6].

Biological fluid samples were sent to the toxicology laboratory in order to rule out the presence of recreational drugs and/or prescribed medicines. The main results of this analysis are shown in Table 1.

\section{PERSONAL HISTORY}

The man's medical records, to which access was granted by a court order, revealed the following information of interest. He had suffered from musculoskeletal problems for the past 5 years and the initial diagnosis was cervicalgia. A year later a diagnosis of cervical osteoarthritis was made, and a year prior to the accident he was diagnosed with spondylosis (chronic dorsalis). Treatment involved anti-inflammatories, muscle relaxants, antidepressants and synthetic opioids. Five years prior to the accident he had been prescribed a synthetic opioid (tramadol $37.5 \mathrm{mg} /$ paracetamol $325 \mathrm{mg}$ ), which he took only sporadically for the first 3 years, but during the past 2 years he had taken between 6 and 12 tablets/day. Six months prior to the accident he had been prescribed venlafaxine $150 \mathrm{mg} /$ day for reactive depression triggered by his chronic pain. He occasionally took diazepam $2 \mathrm{mg}$ at night.

The blood tramadol concentration that was detected post-mortem is 3-4 higher than the maximum therapeutic dose. The analysis was performed using cardiac blood as the purpose was to screen for recreational drugs and prescribed medicines, although in the specific case of tramadol, testing is best performed using femoral blood as the cardiac-to-femo- 
ral blood ratio is 1.4 [7], which in the case of this man would imply a femoral blood concentration of tramadol of $2.1 \mathrm{mg} / \mathrm{L}$.

\section{DISCUSSION}

Mainly, in this case, we will refer to the toxicity of tramadol, because high concentrations in blood have been identified. The rest of the psychotropic drugs concentrations were found within the therapeutic values and they can only increase the effects of tramadol.

Tramadol is a synthetic opioid receptor agonist that is used as an analgesic in cases of moderate or intense pain. It is converted in the liver to 0-desmethyltramadol and several inactive metabolites. The 0-desmethyl metabolite, also known as M1, is 2-4 times more potent than tramadol itself and is primarily responsible for the analgesic effect. Peak plasma concentration is reached within 1-2 hours of oral administration, and therapeutic blood concentrations are in the range $0.1-0.8 \mathrm{mg} / \mathrm{L}$ [8]. Tramadol crosses the bloodbrain barrier and has an elimination half-life of 5-6 hours, while that of its active metabolite is $7-8$ hours. Excretion is primarily via the kidneys.

The analgesic effect of tramadol is mainly due to its action as an inhibitor of serotonin-norepinephrine reuptake in the spinal cord $[1,2]$. Accordingly, the most common adverse reactions to tramadol are nausea and dizziness, which occur in $10 \%$ of patients. Among neurological side effects, headache and drowsiness are the most frequent, although patients may exceptionally experience loss of appetite, paraesthesia, tremor, respiratory depression, seizures, involuntary muscle spasms, problems with coordination or syncope. Respiratory depression can occur when the dose given is much higher than recommended and when the drug is administered simultaneously with other central nervous system (CNS) depressants [9]. The most common psychiatric symptoms associated with the use of tramadol are hallucinations, confusion, sleep disorders (including nightmares) and anxiety. The intensity and nature of adverse psychological effects varies from one individual to another (depending on personality and the duration of drug treatment). Impairment of cognitive and sensory abilities (e.g. decision making, altered perception) may also be observed. Importantly, tramadol can produce dependence.

The use of tramadol in conjunction with other serotoninergic agents, such as SSRIs, or with monoamine oxidase inhibitors may result in a severe serotonin syndrome, which in some cases can be fatal. Notably, the patient in the present case report was taking tramadol in conjunction with venlafaxine (a SSRI). Clarot et al., 2003 [10] examined the combined use of tramadol and 21 other drugs and concluded that benzodiazepines posed a particular risk. Several studies have also documented the neurological effects produced by tramadol overdose.
A study of 190 patients, Marquardt et al., 2005 [11], found that $27.4 \%$ experienced CNS depression, $5.8 \%$ dizziness, $3.7 \%$ confusion, $3.2 \%$ headache and $1.6 \%$ entered a coma. Shadnia et al., 2008 [12] examined 114 cases of intentional tramadol intoxication and found that $71(62.3 \%)$ patients presented vertigo, 40 (35\%) had seizures, 31 (27\%) anxiety and 26 (23.4\%) lost consciousness. Finally, a study by Spiller et al., 1997 [13] of 87 patients found that the symptoms reported with tramadol overdose were lethargy in $26(30 \%)$ cases and coma in 4 (5\%) patients.

Several studies have also examined fatal intoxications involving tramadol. Tjäderborn et al., 2007 [14] analysed 17 cases of unintentional intoxication and found that blood tramadol concentrations at autopsy ranged from 1.1 to $12 \mathrm{mg} / \mathrm{kg}$. De Decker et al., 2008 [15] described 8 cases of fatal intoxication in which tramadol but no other toxic substances were detected in blood. Tramadol concentrations ranged between 1.6 and $15.1 \mathrm{mg} / \mathrm{L}$. Simonsen et al., 2015 [16] conducted an epidemiological study of fatal poisoning in drug addicts over a period of three decades in five Nordic countries. In Finland during the period 2002-2012, deaths due to tramadol accounted for $9-11 \%$ of the total number of cases.

The blood tramadol concentration that was detected in our patient at autopsy is like that reported in several previous cases. It should be noted that tramadol concentrations in cadaveric blood may vary due to post-mortem redistribution, and in this respect, determinations in femoral blood are more reliable [3].

Venlafaxine is an antidepressant that increases neurotransmitter activity in the CNS. Both venlafaxine and its main metabolite 0-desmethylvenlafaxine are potent inhibitors of serotonin-norepinephrine reuptake. Therapeutic doses of venlafaxine range between 75 and $375 \mathrm{mg} /$ day, and peak plasma concentration is reached within 2-3 hours of oral administration. The elimination half-life of venlafaxine is $4-5$ hours, while for 0 -desmethylvenlafaxine it is 11 hours.

Adverse neurological effects associated with venlafaxine administration include dizziness, headache, paraesthesia, sedation and tremor. It may also cause psychiatric symptoms such as insomnia, drowsiness, agitation and sleep disturbance in the form of nightmares. The concomitant use of venlafaxine and tramadol may result in a serotonin syndrome involving both central and peripheral neurological changes, and fatalities have been reported $[17,18]$.

It is relevant to notice that medication use is an important matter to be evaluated from the first and the periodical Medical Fitness Examination, especially if the worker has to perform dangerous activities. As an example, it is clearly included in the Appendix D of the ILO/IMO Guidelines on Medical Examination of Seafarers [19], 
it says "ensure that seafarers are not taking any medication that has side effects that will impair judgement, balance, or any other requirements for effective and safe performance of routine and emergency duties on board" (STCW Code, Section A-I/9, Paragraph 2.5). The examining doctor will need to assess the known adverse effects of each medication used and the individual's reaction to it. This is particularly important for those medications that are controlled drugs or which may be abused. In the first group, we have medications that can impair routine and emergency duties like CNS depressants (e.g. sleeping tablets, antipsychotics, some analgesics, some anti-anxiety and anti-depression treatments and some antihistamines). They may need surveillance requirements and restrictions to certain type of work, more frequently that full duration of the fitness certificate. A follow up of the Occupational Health Department and Risk Prevention Services should be taken into account.

This fatal occupational accident showed a disconnection between the National Health System that controls diseases of non-occupational origin and the occupational health practitioner in charge of monitoring his health surveillance. Normally, only the worker himself, voluntarily, reports his health status to his occupational health service. Without this knowledge, the occupational doctor cannot adequately follow, complete or modify the treatment and propose modifications or changes in his or her job. The company carries out information and training campaigns for its workers, regarding specific occupational risks and health promotion. But it is needed a better communication system. It is a must to show how dangerous, medicines can be, when driving or carrying out dangerous work.

\section{CONCLUSIONS}

Medication can play an important part in enabling the persons to continue to work. And the Occupational Health System and the Risk Prevention Department has to be aware about, to be able to restrict dangerous work from the worker.

In the case reported here, the drugs identified at autopsy may have been interfering with the man's capabilities at the time of the accident. Specifically, the concentrations ingested and detected in the toxicological analysis could have impaired his cognitive and sensory capacity, including his decision-making ability and perception of the environment, and they may have produced symptoms such as confusion and dizziness.

In order to prevent harm to themselves and others, all persons who are prescribed medication that may impair their ability to drive or perform potentially dangerous tasks at work must be properly advised by a physician with regard to the activities that it is safe for them to carry out.

\section{REFERENCES}

1. Sanz-Gallen P. Guía de los principales criterios sobre la utilización de medicamentos que pueden afectar a la conducción de vehículos y a la realización trabajos peligrosos. Foment de Treball. Barcelona.2020. http://www.researchgate.net/publication/338937183.

2. Agencia Española de Medicamentos y Productos Sanitarios. February 2017 [Internet]. Informe sobre el uso de opioides en el periodo 2008-2015. Madrid: AEMPS; 2017. U/OPI/V1/13022017. U/OPI/ V1/13022017 (Cited 2020, Feb 14).

3. Agencia Española de Medicamentos y Productos Sanitarios. March 2019 [Internet] Utilización de medicamentos opioides en España durante el período 2010-2018. Madrid: AEMPS; 2019. https://www.aemps.gob.es/medicamentos-de-uso-humano/ observatorio-de-uso-de-medicamentos/utilizacion-de-medicamentos-opioides-en-espana-durante-el-periodo-2010-2018/ (Cited 2020, Feb 14).

4. Agencia Española de Medicamentos y Productos Sanitarios. January 2015 [Internet]. Informe de Utilización de medicamentos antidepresivos en España durante el periodo 2000-2013. Madrid: AEMPS; 2015. U/AD/V1/14012015. https://www.aemps.gob. es/medicamentosUsoHumano/observatorio/docs/antidepresivos-2000-2013.pdf (Cited 2020, Feb 14).

5. DRUID. Deliverable 4.3.1. Establishment of framework for classification/categorisation and labelling of medicinal drugs and driving. [Internet] Cologne: BASt, 2011. https://www.bast.de/Druid/EN/ deliverales-list/downloads/Deliverable_4_3.pdf?__blob=publicationFile.

6. Teijeira R, Bañón R, Hidalgo A, et al. La autopsia médico-legal. Medicina Clínica. 2006; 126(20): 787-792, doi: 10.1157/13089117.

7. Costa I, Oliveira A, Guedes de Pinho P, et al. Postmortem redistribution of tramadol and 0-desmethyltramadol. J Anal Toxicol. 2013; 37(9): 670-675, doi: 10.1093/jat/bkt084, indexed in Pubmed: 24084873.

8. Randall C, Crane J. Tramadol deaths in Northern Ireland: a review of cases from 1996 to 2012. J Forensic Leg Med. 2014; 23 : 32-36, doi: 10.1016/j.jflm.2014.01.006, indexed in Pubmed: 24661703.

9. Ryan NM, Isbister GK. Tramadol overdose causes seizures and respiratory depression but serotonin toxicity appears unlikely. Clin Toxicol (Phila). 2015; 53(6): 545-550, doi: 10.3109/15563650.2015.1036279, indexed in Pubmed: 25901965.

10. Clarot F, Goullé JP, Vaz E, et al. Fatal overdoses of tramadol: is benzodiazepine a risk factor of lethality? Forensic Sci Int. 2003; 134(1): 57-61, doi: 10.1016/s0379-0738(03)00100-2, indexed in Pubmed: 12842359.

11. Marquardt KA, Alsop JA, Albertson TE. Tramadol exposures reported to statewide poison control system. Ann Pharmacother. 2005; 39(6): 1039-1044, doi: 10.1345/aph.1E577, indexed in Pubmed: 15870139.

12. Shadnia S, Soltaninejad K, Heydari K, et al. Tramadol intoxication: a review of 114 cases. Hum Exp Toxicol. 2008; 27(3): 201-205, doi: 10.1177/0960327108090270, indexed in Pubmed: 18650251.

13. Spiller HA, Gorman SE, Villalobos D, et al. Prospective multicenter evaluation of tramadol exposure. J Toxicol Clin Toxicol. 1997; 35(4): 361-364, doi: 10.3109/15563659709043367, indexed in Pubmed: 9204095. 
14. Tjäderborn M, Jönsson AK, Hägg $S$, et al. Fatal unintentional intoxications with tramadol during 1995-2005. Forensic Sci Int. 2007; 173(2-3): 107-111, doi: 10.1016/j.forsciint.2007.02.007, indexed in Pubmed: 17350197.

15. De Decker K, Cordonnier J, Jacobs W, et al. Fatal intoxication due to tramadol alone. Forensic Science International. 2008; 175(1): 79-82, doi: 10.1016/j.forsciint.2007.07.010.

16. Simonsen KW, Edvardsen HME, Thelander G, et al. Fatal poisoning in drug addicts in the Nordic countries in 2012. Forensic Sci Int. 2015; 248: 172-180, doi: 10.1016/j.forsciint.2015.01.003, indexed in Pubmed: 25645132.
17. Boyer EW, Shannon M. The serotonin syndrome. N Engl J Med. 2005; 352(11): 1112-1120, doi: 10.1056/NEJMra041867, indexed in Pubmed: 15784664.

18. Sansone RA, Sansone LA. Tramadol: seizures, serotonin syndrome, and coadministered antidepressants. Psychiatry (Edgmont). 2009; 6(4): 17-21, indexed in Pubmed: 19724727.

19. ILO-IMO Guidelines on the medical examinations of seafarers. [Internet] International Labour Office. Sectoral Activities Programme; JMS/2011/12- Geneva: ILO, 2013. https://www.ilo. org/wcmsp5/groups/public/-ed_dialogue/--sector/documents/ normativeinstrument/wcms_174794.pdf (Cited 2020, Feb 14). 